(c) American Dairy Science Association, 2006.

\title{
Survey of Management Practices on Reproductive Performance of Dairy Cattle on Large US Commercial Farms
}

\author{
D. Z. Caraviello, ${ }^{\star}$ K. A. Weigel, ${ }^{* 1}$ P. M. Fricke, ${ }^{\star}$ M. C. Wiltbank, ${ }^{*}$ M. J. Florent, ${ }^{*}$ N. B. Cook, $\dagger$ \\ K. V. Nordlund,† N. R. Zwald, $\ddagger$ and C. L. Rawson $\ddagger$ \\ *Department of Dairy Science, and \\ †School of Veterinary Medicine, University of Wisconsin, Madison 53706 \\ $\ddagger$ Alta Genetics, Inc., Watertown, WI 53094
}

\begin{abstract}
A survey regarding general management, sire selection, reproductive management, inseminator training and technique, heat abatement, body condition scoring, facility design and grouping, nutrition, employee training and management, and animal health and biosecurity was carried out from March to September of 2004 in 153 herds in the Alta Genetics (Watertown, WI) Advantage Progeny Testing Program. A total of 103 herds (67.3\%) completed the survey. Herd size was $613 \pm 46$ cows, with herds located in Wisconsin (26), California (12), New York (11), Minnesota (10), Michigan (7), Washington (6), Pennsylvania (6), Iowa (5), Idaho (5), Texas (4), Ohio (4), and other states (7). These farms sold $34.5 \pm 0.3 \mathrm{~kg}$ of milk/d per cow, with an annual culling rate of $34 \pm 1 \%$ and a calving interval of $13.8 \pm 0.1 \mathrm{mo}$. Cows were observed for estrus $2.8 \pm$ 0.3 times/d, for a duration of $27 \pm 4 \mathrm{~min}$, but $78 \%$ of the respondents admitted that detection of estrus was not the employee's sole responsibility at that time. Managers tried to achieve pregnancy until $8.8 \pm 0.9$ failed inseminations, $300 \pm 26 \mathrm{~d}$ postpartum, or milk yield $<17.7 \pm 0.5 \mathrm{~kg} / \mathrm{d}$. Nonpregnant cows were culled at $326 \pm 36 \mathrm{~d}$ postpartum or milk yield $<16.4 \pm 0.3 \mathrm{~kg} /$ d. Mean durations of the voluntary waiting period were $52 \pm 1.3$ and $53 \pm 1.4 \mathrm{~d}$ for primiparous and multiparous cows, respectively. Hormonal synchronization or timed artificial insemination programs were used in $87 \%$ of the herds, with $86 \%$ synchronizing first services, $77 \%$ resynchronizing repeat services, and 59\% treating cystic, anestrous, or anovular cows. Finding good employees was identified as the greatest labor challenge, followed by training and supervising employees. Mastitis and hairy heel warts were noted as the greatest animal health concerns, followed by lameness, abortions, and death losses, whereas the greatest reproductive challenges were artificial insemination service rate, con-
\end{abstract}

Received May 30, 2006.

Accepted July 21, 2006.

${ }^{1}$ Corresponding author: kweigel@wisc.edu ception rate, twinning, and retained placenta or metritis. Results of this study can provide a useful benchmark or reference with regard to commonly used management practices on large commercial US dairy farms at the present time.

Key words: reproduction, fertility, herd management, survey

\section{INTRODUCTION}

The reproductive performance of high-producing dairy cows on modern commercial farms is influenced by a multitude of factors (Westwood et al., 2002; Caraviello et al., 2006). Numerous variables related to energy balance (Veerkamp et al., 2000), BCS (Moreira et al., 2000), milk yield (Veerkamp et al., 2000), disease (Windig et al., 2005), hormonal synchronization (Pursley et al., 1995), and reproductive management (Santos et al., 2004; Moore and Thatcher, 2006) have been associated with differences in reproductive performance in previous studies.

In a series of papers, Bewley et al. (2001a,b,c) and Weigel et al. (2003) presented results of a detailed management survey involving 302 Wisconsin farms that expanded their milking herds significantly between 1994 and 1998. All aspects of these operations, including biosecurity, employee management, housing, bedding, feed delivery, manure removal, stocking density, animal restraint, heat abatement, and fresh cow management, were evaluated as predictors of animal health, milk production, reproductive efficiency, culling rate, labor efficiency, and overall owner satisfaction. Although these studies provided a wealth of information, the survey was limited to herds in Wisconsin, and details regarding specific aspects of reproductive management were not considered.

Therefore, the objective of the present study was to examine current management practices on large commercial dairy farms, paying particular attention to factors that could influence reproductive performance, via an extensive survey of managers of herds that par- 
ticipated in the Alta Genetics (Watertown, WI) Advantage Progeny Testing Program.

\section{MATERIALS AND METHODS}

A comprehensive survey was developed that included questions regarding 10 aspects of each dairy operation, including general management issues, sire selection, reproductive management, inseminator training and techniques, heat abatement devices, body condition scoring, facility design and pen movement, nutrition, employee training and management, and animal health and biosecurity. Between March and September 2004, this survey was delivered to each of 153 large commercial dairy farms that participated in the Alta Genetics Advantage Program, a program for concentrated progeny testing of elite young Holstein sires in large herds, by an Advantage Program consultant, who assisted the herd manager in completing the survey. These herds were located in Wisconsin (26), California (12), New York (11), Minnesota (10), Michigan (7), Washington (6), Pennsylvania (6), Iowa (5), Idaho (5), Texas (4), Ohio (4), and other states (7). Means and corresponding standard errors were computed for continuous and ordinal variables, whereas frequencies were tabulated for binary and categorical variables.

\section{RESULTS AND DISCUSSION}

A total of 103 of the 153 herds receiving a survey responded, resulting in a $67.3 \%$ response rate. The response rate was relatively high, because most of these herds have a long-standing relationship with Alta Genetics and, more important, because Advantage Program consultants assisted herd managers in completing the survey. Mean herd size of respondents was $613 \pm 46$ lactating cows.

Table 1 provides a summary of information regarding labor, herd size, milk production, calving interval, culling, management of nonpregnant cows, and use of Posilac (recombinant bST, rBST) on these farms. Managers anticipated continued expansion, because the mean 5-yr goal for herd size of $942 \pm 94$ cows (ranging from 150 to 7,000 cows) represented a $54 \%$ increase from the current mean of $613 \pm 46$ cows. Approximately $73 \%$ of labor was provided by nonfamily employees, with most of these employees working full-time. Based on a 50 -h work week, the average number of cows per full-time equivalent employee in the dairy operation was 84 , which was greater than that reported for recently expanded Wisconsin herds surveyed by Bewley et al. (2001c). The most frequent employee benefits were paid vacation time and housing, which were of- fered on a greater percentage of farms than reported by Bewley et al. (2001b). Roughly one-half of the farms provided health insurance, but few offered profit sharing. Managers identified finding good employees as the greatest labor management challenge, followed by training and supervising employees, whereas employee absences and employee retention were not considered problematic. Respondents to the survey of Bewley et al. (2001b) also identified finding good employees as the top labor management challenge, followed by training employees, although employee retention was considered more problematic than in the present study.

Mean daily milk yield, expressed as the amount of milk sold per cow per day, was $34.5 \pm 0.3 \mathrm{~kg}$ (with SD of $3.0 \mathrm{~kg}$ ), whereas means for annual culling rate and calving interval were $34 \pm 1 \%$ (with SD of $7.4 \%$ ) and $13.8 \pm 0.1 \mathrm{mo}$ (with SD of $0.6 \mathrm{mo}$ ), respectively. Mean culling rate and calving interval in 1998 in recently expanded Wisconsin herds surveyed by Bewley et al. (2001b) were similar, at $33.2 \pm 0.7 \%$ and $13.8 \pm 0.1 \mathrm{mo}$, respectively. All of these herds used predominantly AI sires, which was expected given that heavy usage of young sire semen was a key requirement of the Advantage Progeny Testing Program. A total of 44 herds used a clean-up bull, and nonpregnant cows were moved to the clean-up pen after $6.6 \pm 0.6$ failed inseminations or $232 \mathrm{~d} \pm 9 \mathrm{~d}$ postpartum. Interestingly, these managers kept trying to achieve pregnancy until cows reached $8.8 \pm 0.9$ failed inseminations, $300 \pm 26 \mathrm{~d}$ postpartum, or when milk yield dropped below $17.7 \pm 0.5 \mathrm{~kg} / \mathrm{d}$. Culling of nonpregnant cows occurred shortly thereafter, at $326 \pm 36 \mathrm{~d}$ postpartum, or when milk yield was less than $16.4 \pm 0.3 \mathrm{~kg} / \mathrm{d}$. By comparison, de Vries and Risco (2005) reported a mean of $415 \mathrm{~d}$ until culling of nonpregnant cows in Florida and Georgia, with a corresponding minimum milk yield of nonpregnant cows of $12.3 \mathrm{~kg} / \mathrm{d}$. Posilac (rBST) was used in 71 herds, with $41 \%$ of cows in these herds receiving Posilac every other week from $97 \pm 6 \mathrm{~d}$ postpartum through the end of lactation, regardless of pregnancy status. However, usage may have been reduced because of limited availability of Posilac at the time of this survey. Managers indicated that a slightly lower proportion of herds and cows would use Posilac in the future, but that Posilac treatment would begin earlier in lactation than at present.

Table 2 provides a summary of responses regarding detection of estrus, hormonal synchronization, and use of a voluntary waiting period (VWP) to determine the minimum number of days to first insemination. Most herds used on-farm labor for detection of estrus, and cows were observed $2.8 \pm 0.3$ times on weekdays and $2.5 \pm 0.2$ times on weekends, for an average duration of 
Table 1. Summary of responses by herd managers $(n=103)$ to questions related to labor, herd size, milk production, calving interval, culling, management of nonpregnant cows, and use of Posilac (rBST), along with corresponding means \pm SE (continuous variables) or counts (binary or categorical variables)

Question
How many people are involved in the management
and work of your operation?
Full-time family
Part-time family
Full-time nonfamily
Part-time nonfamily
What benefits do you offer full-time employees?

Please describe the following aspects of employee management on your operation $(1=$ not a problem to $5=$ major problem $)$

Finding good employees

Training employees

Supervising employees

Keeping good employees

Employee absences

What is your 5-yr goal for herd size?

Do you have any breeds other than Holstein in your herd?

How much milk do you ship per cow per day?

What percentage of your cows left the herd last year?

When do you decide to cull nonpregnant cows?

Failed inseminations

Days postpartum

Milk production

When do you cull nonpregnant cows?

Days postpartum

Milk production

What is the extent of AI use in your herd?

When do you move cows to the clean-up bull pen?

Failed inseminations

Days postpartum

Do you use male fertility data when selecting AI sires?

Do you use female fertility data when selecting AI sires?

Do you use Posilac (rBST)?

What percentage of cows receive Posilac?

When do you start giving Posilac?

What injection interval do you use?

Do nonpregnant cows receive Posilac?
What is the average calving interval in your herd?

Response (number)

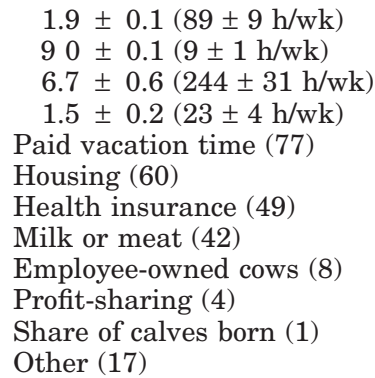

Paid vacation time (77)

Housing (60)

Health insurance (49)

Milk or meat (42)

Employee-owned cows (8)

Profit-sharing (4)

Share of calves born (1)

Other (17)

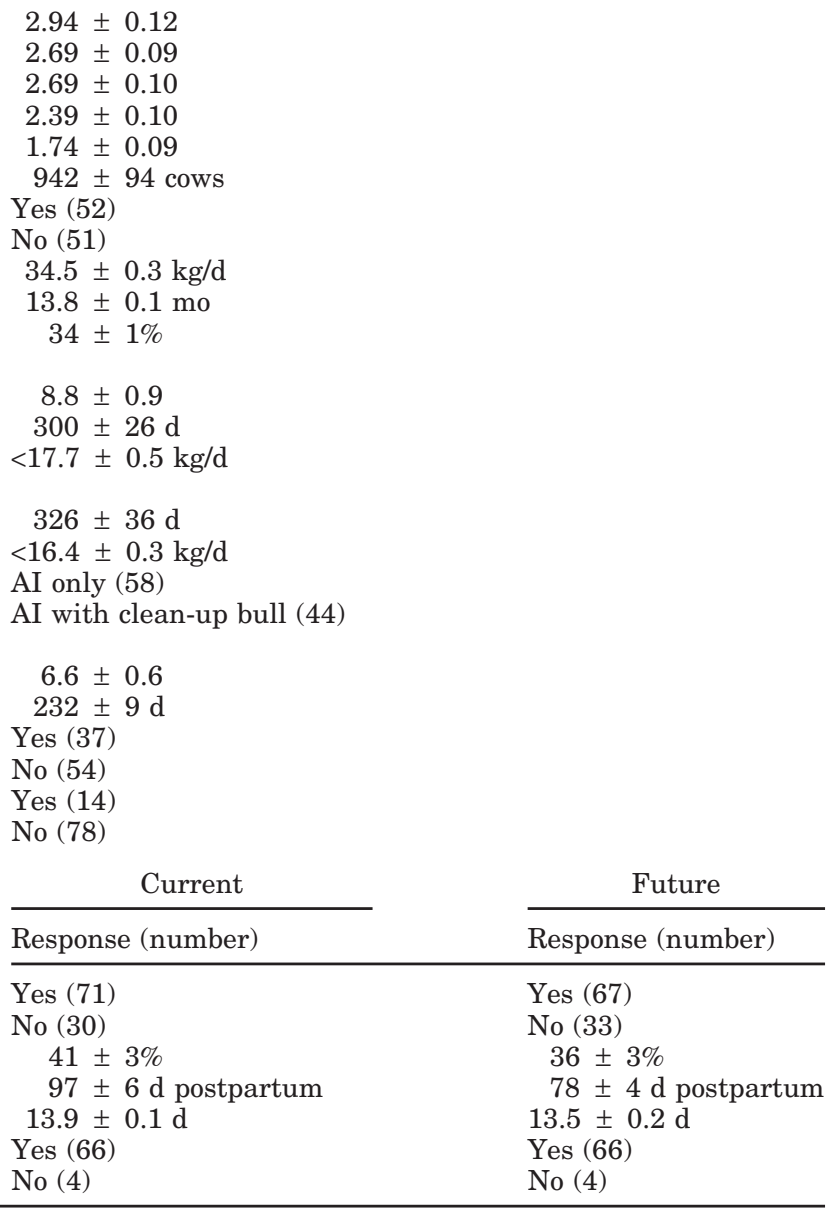

observation of $27 \pm 4 \mathrm{~min}$ and $25 \pm 4 \mathrm{~min}$, respectively. Interestingly, 78 herds admitted that detection of estrus was not the employee's sole responsibility during this period, so "multitasking" appears to be a widespread and limiting factor with respect to estrus detection efficiency. Among estrus detection aids, tail chalk was most commonly used, with few herds using pedom-

eters or pressure-activated rump-mounted patches. Nearly all herds used a VWP, with a mean duration of $52 \pm 1.3 \mathrm{~d}$ for primiparous cows and $53 \pm 1.4 \mathrm{~d}$ for multiparous cows. About one-quarter of herds indicated that the duration of the VWP for an individual cow depended on milk yield, BCS, or other factors. In a recent study, Stevenson and Phatak (2005) noted 
Table 2. Summary of responses by herd managers $(n=103)$ to questions related to detection of estrus, hormonal synchronization, and voluntary waiting period, along with corresponding means $\pm \mathrm{SE}$ (continuous variables) or counts (binary or categorical variables)

Question
Who is responsible for estrus detection on your farm? (check
How many times per day do they watch cows for estrus?
Weekdays
Weekends
How much time is spent on detection of estrus each time?
Weekdays
Weekends
Is detection of estrus their sole responsibility at this time?

Where are cows observed for estrus? (check all that apply)

What estrus-detection aids are used? (check all that apply)

How were staff responsible for estrous detection trained?

Do you use a voluntary waiting period?

Does your voluntary waiting period vary by these factors? (check all that apply)

Do you use estrous synchronization and/or timed AI?

For what do you use estrous synchronization or timed AI? (check all that apply)

Which commercial $\mathrm{PGF}_{2 \alpha}$ products do you use? (check all that apply)

Which commercial GnRH products do you use? (check all that apply)

Which protocol is most often used to resynchronize cows for second and later services (refer to Figure 1)

Which protocol is most often used to breed cows with ovarian cysts (refer to Figure 1)

Which protocol is most often used to breed anestrous or anovular cows (refer to Figure 1)

Response (number)

Hired employee (78)

Family member (50)

AI stud employee (15)

Other (15)

$2.8 \pm 0.3$

$2.5 \pm 0.2$

$27 \pm 4 \mathrm{~min}$

$25 \pm 4 \mathrm{~min}$

Yes $(22)$

No (78)

Barn (82)

To or from parlor (59)

Parlor (37)

Other (24)

Tail chalk (60)

Pedometers (8)

Pressure patches (3)

Other (9)

On-farm (75)

Off-farm (7)

Yes (97)

Primiparous: $52 \pm 1.3 \mathrm{~d}$

Multiparous: $53 \pm 1.4 \mathrm{~d}$

No (5)

Milk production (28)

Body condition score (25)

Other (23)

Yes (90)

No (13)

Setting up cows for first service (77)

Resynchronizing second and later services (69)

Breeding cows with ovarian cysts (53)

Breeding anestrous or anovular cows (53)

Synchronizing embryo transfer recipients (10)

Other (7)

Lutalyse (76)

Prostamate (42)

Estrumate (9)

Cystorelin (66)

Factrel (37)

Fertagyl (21)

Other (24)

OvSynch (50)

HeatSynch (5)

PreSynch (4)

Other (13)

OvSynch (50)

HeatSynch (4)

PreSynch (2)

Other (8)

OvSynch (43)

HeatSynch (3)

PreSynch (3)

Other (7) that delaying first $\mathrm{AI}$ resulted in an increase in conception rate. The majority of herds used hormonal synchronization or timed AI programs. A description of the Ovsynch, Presynch + Ovsynch, and HeatSynch protocols (Pursley et al., 1995; Navanukraw et al., 2004;
Moore and Thatcher, 2006), as shown in Figure 1, was provided to each farm as an appendix to the management survey. The most common strategies for use of synchronization protocols included setting up cows for first postpartum service (77 herds), resynchronizing 
OvSynch (No $\mathrm{PGF}_{2 \alpha}$ injections before the 1 st GnRH injection)

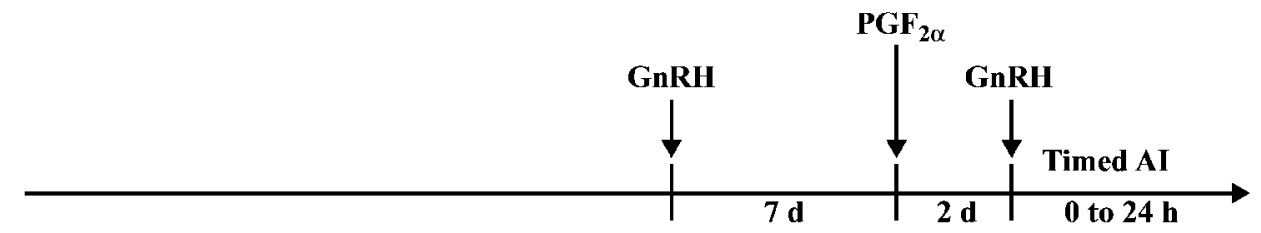

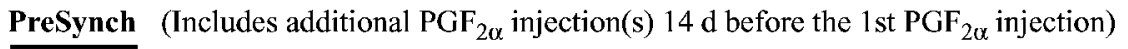

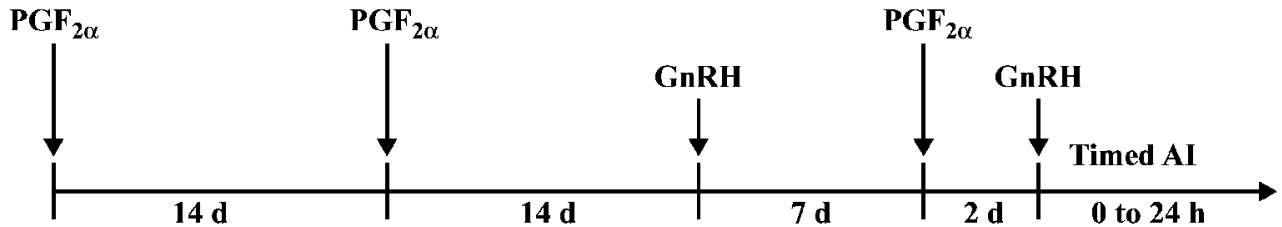

HeatSynch (Modification of Ovsynch or Presynch in which ECP is used in place of the 2nd GnRH injection)

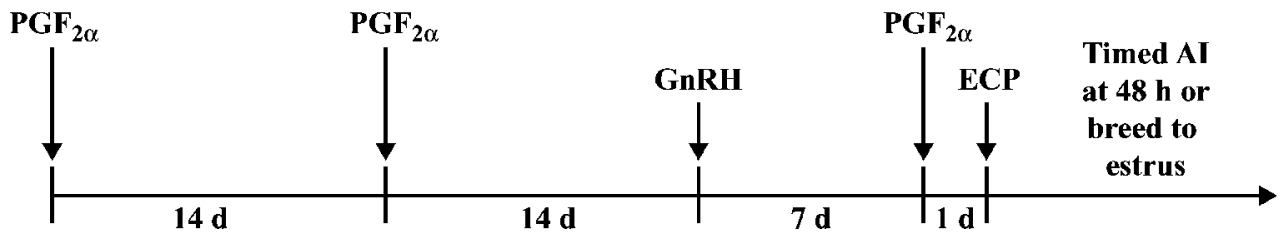

Figure 1. Diagrams of 3 common synchronization protocols for milking cows. ECP = estradiol cypionate.

cows for second and greater services (69 herds), and treatment of cystic, anestrous, or anovular cows (53 herds). The majority of herds indicated use of Ovsynch, with the exception of setting up cows for first service, in which Presynch + Ovsynch was most commonly used. Several studies have reported that presynchronization can improve the pregnancy rate to first postpartum timed AI, relative to Ovsynch alone (El-Zarkouny et al., 2004; Navanukraw et al., 2004).

Table 3 provides a summary of information regarding breeding procedures, pregnancy examinations, and managers' perceived reproductive challenges. The majority of herds used rectal palpation for pregnancy diagnosis, with a mean interval between examinations of $20.8 \pm 1.7 \mathrm{~d}$ and a mean time to reexamination of pregnant cows of $118 \pm 6 \mathrm{~d}$ after insemination. Interestingly, nearly $30 \%$ of these herds used ultrasound for conducting pregnancy diagnoses, indicating that ultrasound is beginning to displace rectal palpation as the method of choice for pregnancy diagnosis in some herds. Fricke (2002) noted the importance of early and accurate detection of nonpregnant cows, although recent reports have questioned the efficacy of conducting pregnancy diagnosis using ultrasound earlier than 30 to $40 \mathrm{~d}$ after timed AI (Sterry et al., 2006). Among the reproductive challenges identified by herd managers,
AI service rate, conception rate, twinning, and retained placenta or metritis were noted most frequently. Detection of estrus and early embryonic loss were of intermediate concern, whereas ovarian cysts and (especially) reproductive record keeping were not considered problematic. As noted in Table 3, a total of 68 herds had self-locking manger head gates, whereas the remainder inseminated cows in the free stalls (24 herds) or used a palpation rail ( 21 herds). Bewley et al. (2001a) found no significant difference between selflocking head gates and palpation rails in terms of labor efficiency, ease of use, or worker safety. Most breeding technicians were trained on farm, and the vast majority used water thawing of semen at approximately $35^{\circ} \mathrm{C}$ for 35 to $40 \mathrm{~s}$. The technicians surveyed indicated that they typically thawed no more than 3 straws of semen at a time. Dalton et al. (2004) found no association between conception rate and insemination sequence in lactating Holstein cows when up to 4 straws of AI semen were thawed simultaneously.

Table 4 summarizes housing, heat stress, and manure removal strategies on farms. Nearly all herds provided shade throughout the day, and most also shaded parlor walkways and holding pens. Only 15 herds used wind tunnel ventilation, whereas 83 used recirculation fans, and 69 used soakers (sprinklers). 
Table 3. Summary of responses by herd managers $(n=103)$ to questions related to breeding procedures, pregnancy diagnosis, and reproductive challenges, along with corresponding means $\pm \mathrm{SE}$ (continuous variables) or counts (binary or categorical variables).

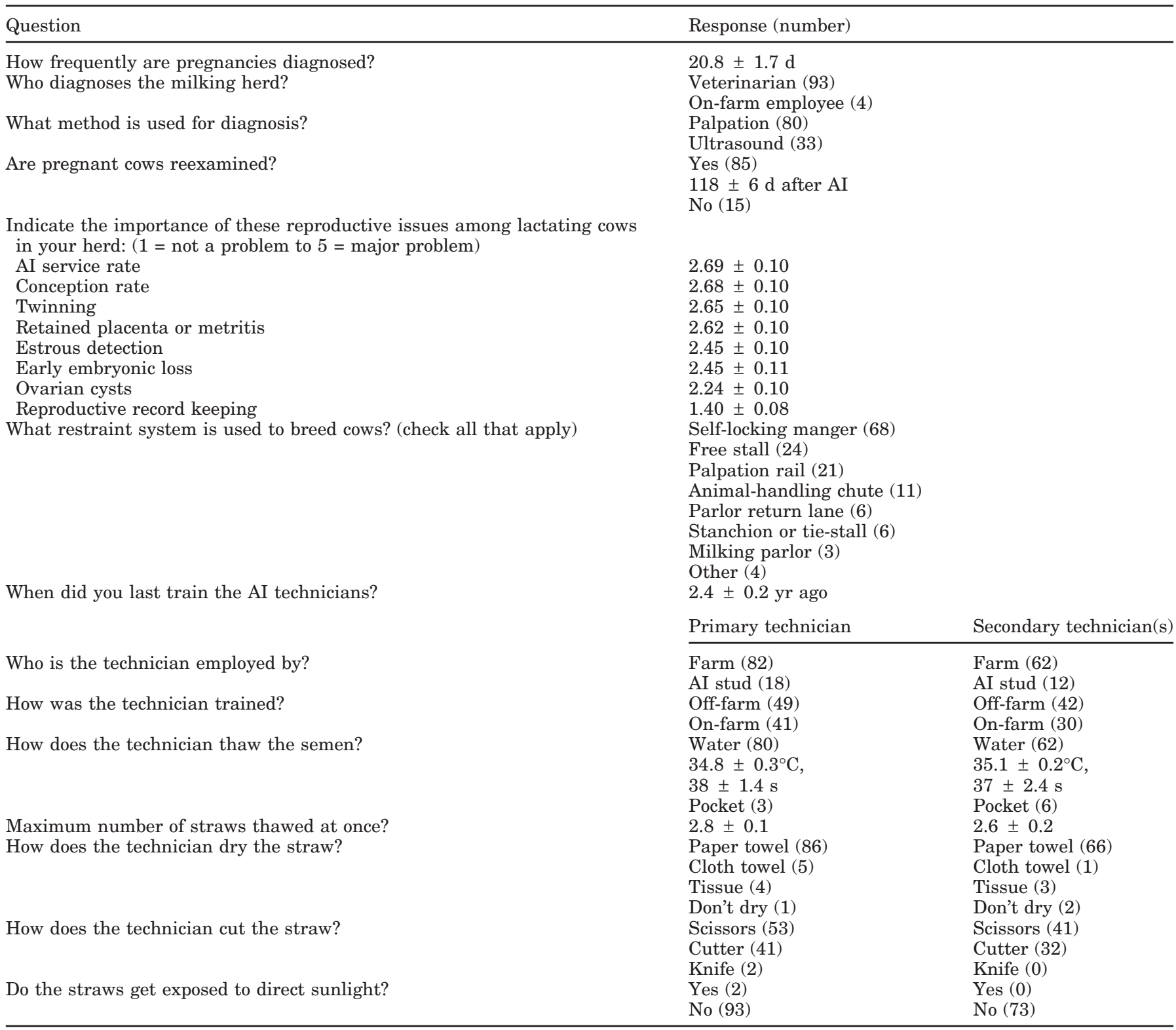

These herds are located throughout the United States, so the absence of heat abatement devices generally applies to herds in the northern states, although Fricke et al. (2002) noted that conception rates are reduced during the summer in northern Wisconsin as well. As noted in Table 4, fresh bedding is applied every $2.4 \pm$ $0.3 \mathrm{~d}$. However, fewer than half of respondents indicated that maternity pens were cleaned after every calving, and many indicated that $\geq 4$ calvings occur between successive cleanings. This is in contrast to the recommendation of Elbers et al. (1998), who noted the importance of disinfecting the maternity pen after calving with respect to management of clinical masti- tis. The vast majority of cows were housed on concrete, which increases the risk of lameness (Cook et al., 2004) and decreases expression of estrus behavior (Vailes and Britt, 1990). A total of 44 herds reported that cows had feet trimmed $>3$ times per year, whereas 21 herds performed maintenance trimming only once a year or less, suggesting a wide variation in hoof care management on these farms. However, almost all herds used a foot bath to control infectious causes of lameness.

Table 5 summarizes data regarding nutrition and BCS. Drive-through feeding was the most common means of feed delivery, presumably because of high producer satisfaction with this practice, as noted in the 
Table 4. Summary of responses by herd managers $(n=103)$ to questions related to housing, heat stress, and manure removal, along with corresponding means $\pm \mathrm{SE}$ (continuous variables) or counts (binary or categorical variables).

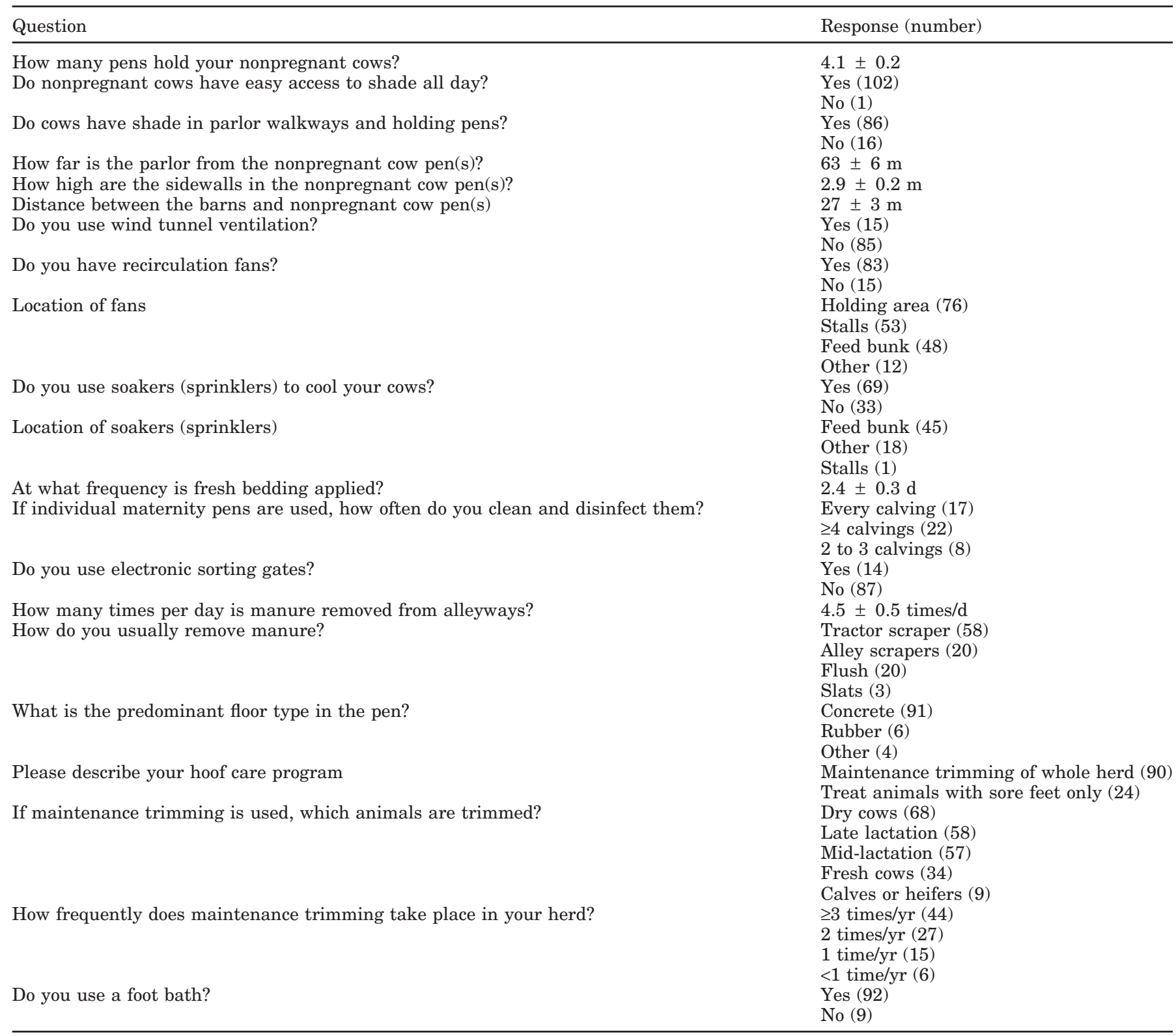

survey of Bewley et al. (2001a). The mean frequency of feed delivery was $1.8 \pm 0.1$ times/d, and feed was pushed up an average of $6.8 \pm 0.4$ times/d. DeVries et al. (2005) noted that increasing the frequency of feed delivery from once to twice daily reduced the amount of feed sorting and improved access to fresh feed for all cows during peak feeding periods. Stone (2004) recommended that feed should be pushed up 8 to 10 times daily to encourage adequate intake and to minimize sorting. The mean targeted feed refusal rate was 3.5 $\pm 0.2 \%$ of feed delivered, whereas the mean amount of bunk space per cow was $52.6 \pm 1.5 \mathrm{~cm}$ in the main breeding pen and $56.4 \pm 2.5 \mathrm{~cm}$ in other pens that contained nonpregnant cows. Cook et al. (2004) noted the importance of adequate bunk space with respect to avoidance of metabolic disorders and reported means of 46 and $74 \mathrm{~cm} / \mathrm{cow}$ in fully stocked 3-row and 2-row free-stall barns, respectively. Diets were reformulated and feeds were tested approximately once per month ( $28 \pm 5$ and $24 \pm 2$-d intervals, respectively), and responsibilities for diet formulation were shared primarily between feed company nutritionists (48 herds) and private nutrition consultants (42 herds). The mean percentage of $\mathrm{CP}$ in the nonpregnant cow 
Table 5. Summary of responses by herd managers $(n=103)$ to questions related to nutrition and body condition scoring, along with corresponding means $\pm \mathrm{SE}$ (continuous variables) or counts (binary or categorical variables)

Question
How are your cows typically fed?
At what frequency is fresh feed delivered?
How many times is feed pushed up each day?
How much bunk space per cow in the main breeding pen?
How much bunk space per cow in other breeding pens?
What is the targeted feed refusal rate?
How often are your feeds tested?
How often are the diets reformulated?
Who is the main person responsible for formulating diets?

What is the percentage of $\mathrm{CP}$ in the nonpregnant cow diet? What proportion is RDP?

Is urea fed to nonpregnant cows?

Percentage of NDF in nonpregnant cow rations

Percentage of nonfermentable carbohydrates in these rations

Percentage of fat in nonpregnant cow rations

Percentage of phosphorous in nonpregnant cow rations

How often do you BCS your cows?

When were cows in the breeding pen(s) scored most recently? When had cows in the breeding pen(s) been scored previously? Which pens are routinely scored?

Who does the BCS?

Does the nutritionist use these scores when balancing rations?
Response (number)

Drive-through (67)

Drive-by (19)

Outside feeding $(9)$

$1.8 \pm 0.1 \mathrm{times} / \mathrm{d}$

$6.8 \pm 0.4 \mathrm{times} / \mathrm{d}$

$52.6 \pm 1.5 \mathrm{~cm} / \mathrm{cow}$

$56.4 \pm 2.5 \mathrm{~cm} / \mathrm{cow}$

$3.5 \pm 0.2 \%$ of feed delivered

$24 \pm 2 \mathrm{~d}$

$28 \pm 5 d$

Feed company nutritionist (48)

Private consultant (42)

Veterinarian (5)

On-farm employee (1)

Other (4)

$17.8 \pm 0.1 \%$ (DM basis)

$51.7 \pm 2.1 \%$ (of CP)

Yes (43)

$53 \pm 6 \mathrm{~mL} / \mathrm{cow}$

No (44)

$30.8 \pm 0.6 \%$

$38.9 \pm 0.7 \%$

$5.0 \pm 0.1 \%$

$0.44 \pm 0.03 \%$

Never (53)

Evaluate at pen level every $30 \pm 6 \mathrm{~d}$ (31)

Evaluate cows individually every $59 \pm 23 \mathrm{~d}$ (12)

$70 \pm 36 \mathrm{~d}$ prior to the survey

$123 \pm 56 \mathrm{~d}$ prior to the survey

Yearling heifers (81)

Nonpregnant cows (75)

Cows calved $\leq 10 \mathrm{~d}(72)$

Nonlactating cows (71)

All pens (70)

Nutritionist (26)

Farm employee (12)

Other (9)

Yes (35)

No (10) diet was $17.8 \pm 0.1 \%$, on a DM basis, and the mean percentage of RDP (of total CP) was $51.7 \pm 2.1 \%$. The mean percentage of $\mathrm{CP}$ was in close agreement $(17.5 \%)$ with Godden et al. (2001) in Ontario herds, although the mean percentage of RDP was $65.5 \%$ in the Ontario study. Roughly half of the herds (43 of 87 herds that responded to the question) fed urea, at $53 \pm 6 \mathrm{~mL} / \mathrm{d}$ per cow. Mean percentages of NDF and nonfermentable carbohydrates were $30.8 \pm 0.6$ and $38.9 \pm 0.7 \%$, respectively, which were very similar to the 31.3 and $39.4 \%$, respectively, in the study of Godden et al. (2001). Mean percentages of fat and phosphorous in the diet were $5.0 \pm 0.1$ and $0.44 \pm 0.03 \%$, respectively. Responses regarding evaluation of BCS were somewhat inconsistent, although nearly all herds evaluated heifers, cows recently calving, nonpregnant cows, and nonlactating cows periodically, with pens of nonpregnant cows evaluated at roughly 2 -mo intervals. The importance of BCS with respect to postpartum health and fertility is well documented (e.g.,Veerkamp et al., 2000). Furthermore, BCS near the time of timed AI after Presynch + Ovsynch is inversely related to fertility (Moreira et al., 2000).

Table 6 documents the type of housing, group size, and pen movement strategy on farms. Mean entry and exit dates for the pregnant, nonlactating cows ("far-off dry cow pen") were $52.5 \pm 1.2$ and $20.7 \pm 0.7 \mathrm{~d}$ prepartum, respectively. Mean group size was $60 \pm 4$ cows, with free stall ( 47 herds) and bedded pack ( 15 herds) as the most common housing types, and with sand (30 herds), mattresses (14 herds), and sawdust (13 herds) as the most common bedding types. Mean entry and exit dates for the "close-up dry cow pen" were $20.3 \pm$ 1.3 and $3.1 \pm 0.8 \mathrm{~d}$ prepartum, respectively, whereas mean group size was $41 \pm 4$ cows. Bedded packs (29 herds) were used more commonly, relative to free-stall housing ( 38 herds), than in the far-off dry cow pens. Sand (26 herds) was again the preferred type of bed- 
Table 6. Summary of information provided by herd managers $(n=103)$ relative to grouping strategies and pen movements, along with corresponding means $\pm \mathrm{SE}$ (continuous variables) or counts (binary or categorical variables)

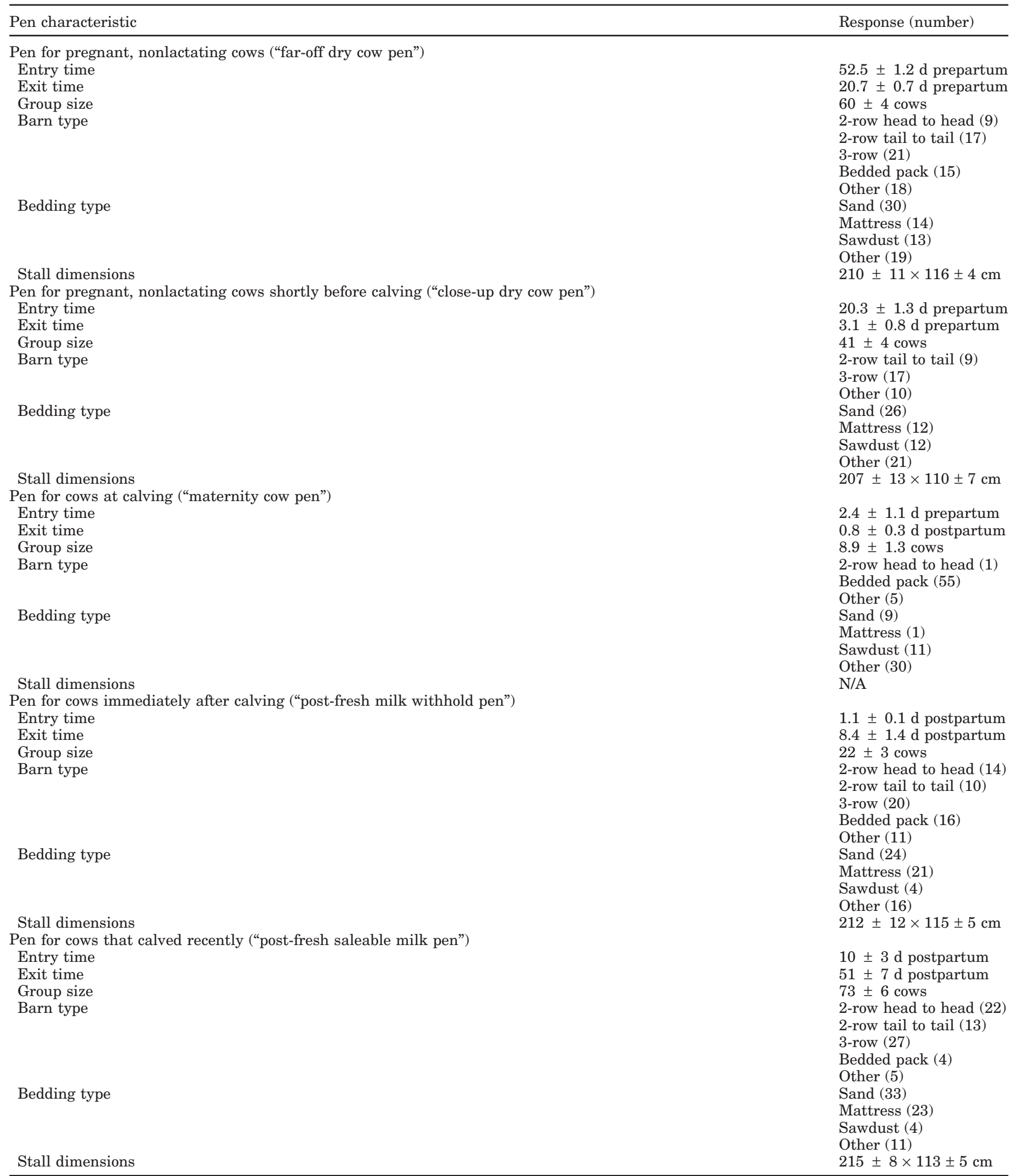


ding, followed by mattresses and sawdust (12 herds each). Contreras et al. (2004) documented the effects of dry cow grouping strategy on health, body condition, and fertility and recommended a 2-group nutritional strategy for dry cows. Mean entry and exit dates for the "maternity cow pen" were $2.4 \pm 1.1 \mathrm{~d}$ prepartum and $0.8 \pm 0.3 \mathrm{~d}$ postpartum, respectively. Average group size was $8.9 \pm 1.3$ cows, with a bedded pack (55 herds) as the most common type of housing. Weigel et al. (2003) reported a significantly lower risk of involuntary culling in herds with individual maternity pens. In the immediately after calving pen ("postfresh milk withhold pen"), mean group size was $22 \pm 3$ cows, with mean entry and exit dates of $1.1 \pm 0.1 \mathrm{~d}$ and $8.4 \pm$ $1.4 \mathrm{~d}$ postpartum, respectively. Free-stall housing (44 herds) was most common, with sand ( 24 herds) and mattresses ( 21 herds) used for bedding. Weigel et al. (2003) and Bewley et al. (2001a) reported a reduced risk of involuntary culling and increased cow comfort in herds that used sand bedding, rather than mattresses. Last, the after-calving pen ("postfresh saleable milk pen") contained $73 \pm 6$ cows, with mean entry and exit dates of $10 \pm 3 \mathrm{~d}$ and $51 \pm 7 \mathrm{~d}$ postpartum, respectively. Once again, free-stall housing (62 herds) was most common, with sand ( 33 herds) or mattresses (23 herds) as the preferred bedding choice. Average stall dimensions were largest in the postfresh saleable milk pen, at $215 \pm 8$ by $113 \pm 5 \mathrm{~cm}$, whereas average dimensions were smallest in the close-up dry cow pen, at $207 \pm 13$ by $110 \pm 7 \mathrm{~cm}$, most likely indicating the use of older barns to house dry cows. Tucker et al. (2004) reported higher average lying time in wide (126 or $132 \mathrm{~cm}$ ) vs. narrow (106 or $112 \mathrm{~cm}$ ) stalls, although stall width did not influence the number of lying events or milk yield.

Table 7 summarizes responses regarding animal health and biosecurity on farms that responded to the management survey. As expected, these herds were in a continuous state of expansion, with annual purchases ranging from $63 \pm 16$ cows (in 2000) to $109 \pm$ 25 cows (in 2002). Pregnant heifers with increasing mammary gland development ("springing heifers") were purchased most frequently (63 herds), whereas in roughly equal numbers of herds (37 and 35, respectively) fresh primiparous cows and multiparous cows were purchased. Bewley et al. (2001b) noted that in $66 \%$ of expanding herds surveyed in Wisconsin, respondents purchased springing heifers, whereas $63 \%$ bought multiparous animals, and $21 \%$ purchased recently calved primiparous cows. Respondents to this survey indicated that only $37 \pm 4 \%$ of purchased animals were sire-identified. Lack of sire identification among purchased animals is a common problem in expanding herds, because it causes records from these animals to be discarded from the national genetic evaluation system and precludes the use of computerized mating programs to control inbreeding. Strategies to minimize health problems when purchasing animals varied widely, with visual inspection prior to purchase (66 herds), vaccination of new cattle before (41 herds) or after purchase (51 herds), increased vaccination of the existing herd ( 24 herds), and quarantine of purchased animals ( 23 herds) as the most commonly used precautions. Bewley et al. (2001b) reported similar trends in expanding Wisconsin herds, with visual inspection before purchase used in $91 \%$ of herds, increasing the vaccination level of the existing herd used in $67 \%$, and vaccination of new cattle before or after purchase used in 49 and $51 \%$, respectively. Disease exposure can occur when heifers are sent to a multiplesource custom raiser, although this occurred in only 15 herds, as 68 raised their own heifers and 12 used a single-source custom calf raiser. In the survey of expanded Wisconsin herds (Weigel et al., 2003), 26\% of farms sent heifers to a custom raiser.

Respondents were asked to indicate vaccines or injections that were typically used, as well as to rank the significance of various diseases as problems in their herds $(1=$ no problem, $2=$ slight problem, $3=$ major problem). Nearly all herds vaccinated animals for bovine viral diarrhea, infectious bovine rhinotracheitis, and leptospirosis (including 38 herds that used Spirovac specifically for Lepto Hardjo-bovis), although the use of Endovac ( 73 herds) and J-5 or J-Vac (45 herds) was also very common. In addition, 45 herds used supplemental vitamin $\mathrm{E}$ and selenium, in addition to that which was available in the diet. Among the health problems listed in Table 7 , mastitis $(2.17 \pm 0.05$ on a 3 -point scale) and hairy heel warts $(2.15 \pm 0.05)$ were of greatest concern, followed by lameness $(2.01 \pm 0.06)$, abortions (1.94 \pm 0.04$)$, cow death losses $(1.88 \pm 0.06)$, Johne's disease $(1.76 \pm 0.07)$, and ketosis $(1.64 \pm 0.05)$. Although Bewley et al. (2001b) did not consider specific diseases or disorders, mastitis was the most commonly reported animal health problem in recently expanded Wisconsin herds.

\section{CONCLUSIONS}

The present study provides a comprehensive summary of management practices, particularly those related to reproductive performance, on large, well-managed commercial dairy farms located throughout the United States. As such, it can serve as a useful reference regarding current practices in various aspects of modern dairy operations, including general management issues, sire selection, reproductive management, inseminator training and techniques, heat abatement 
Table 7. Summary of responses by herd managers $(n=103)$ to questions related to animal health and biosecurity, along with corresponding means \pm SE (continuous variables) or counts (binary or categorical variables)

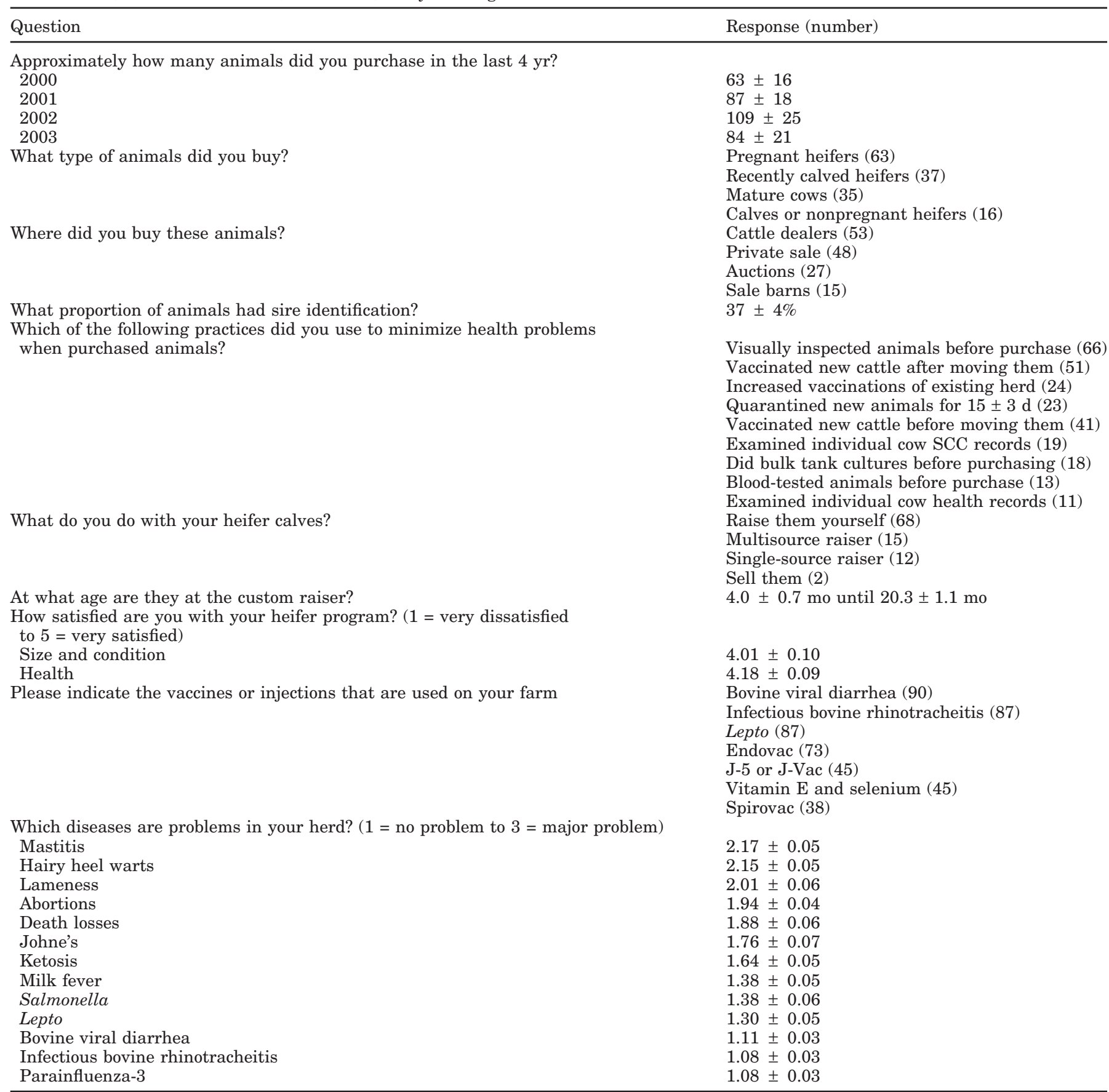

devices, BCS, facility design and pen movement, nutrition, employee training and management, and animal health and biosecurity.

Several key challenges and opportunities were identified in the present survey. Managers identified finding good employees as their greatest labor management challenge, although training and supervision of employees were also considered as challenging on many farms. Mastitis, hairy heel warts, lameness, abortions, death losses, Johne's disease, and ketosis were identified as the most critical animal health concerns on these dairy farms. These herds were in a continuous state of expansion, with plans to increase the milking herd by more than $50 \%$ in the next $5 \mathrm{yr}$. However, fewer than $40 \%$ of animals purchased over the past $5 \mathrm{yr}$ were sire-identified. As such, it is likely 
that many purchased animals have poor genetic merit, and effective control of inbreeding in their progeny will be impossible. Additional opportunities may exist with regard to cleanliness of maternity pens, hoof trimming, and stall size. Fewer than half of respondents cleaned maternity pens after every calving, whereas many allowed $\geq 4$ calvings between successive cleanings. In addition, many herds reported that maintenance hoof trimming took place at a frequency of once a year or less. Stall dimensions were adequate in the postcalving saleable milk pens, but other groups of animals, particularly nonlactating pregnant cows, were housed in older facilities with smaller stalls.

With regard to reproductive management, several key challenges were identified, including AI service rate, conception rate, twinning, and retained placenta or metritis. Among aids for detection of estrus, use of tail chalk was common, but few herds used pedometers or pressure-release patches. Nonpregnant cows were observed for estrus 3 times a day, for approximately 30 min per period, but it is of concern that nearly $80 \%$ of farms admitted to "multitasking" of other management activities during detection of estrus. These herds kept trying to achieve pregnancy in problem breeders well beyond peak lactation, with repeat inseminations continuing through nearly 9 failed inseminations, 300 d postpartum, or milk yield $<18 \mathrm{~kg} / \mathrm{d}$, although one might question the value of achieving pregnancy at such a late stage in lactation. Nearly all farms used a VWP, although the average length of the VWP was just over $50 \mathrm{~d}$ in both primiparous and multiparous cows, and extending the time until first insemination might enhance the first-service conception rate. As expected, the vast majority of herds used hormonal synchronization or timed AI programs, and as such, the dedication of vast research resources to development and optimization of such programs in recent years appears justified. In summary, this study can provide a useful benchmark or reference with regard to commonly used management practices on large commercial US dairy farms at the present time.

\section{ACKNOWLEDGMENTS}

The authors would like to thank Alta Genetics for providing financial support and staff time for this project; the efforts of Advantage Program consultants in delivering and assisting with completion of the surveys described herein were particularly important. Cooperation by managers of herds participating at the Alta Genetics Advantage Program is also gratefully acknowledged. The authors gratefully acknowledge support provided to Daniel Caraviello by the Louis and
Elsa Thomsen Wisconsin Distinguished Graduate Fellowship.

\section{REFERENCES}

Bewley, J., R. W. Palmer, and D. B. Jackson-Smith. 2001a. A comparison of free-stall barns used by modernized Wisconsin dairies. J. Dairy Sci. 84:528-541.

Bewley, J., R. W. Palmer, and D. B. Jackson-Smith. 2001b. An overview of experiences of Wisconsin dairy farmers who modernized their operations. J. Dairy Sci. 84:717-729.

Bewley, J., R. W. Palmer, and D. B. Jackson-Smith. 2001c. Modeling milk production and labor efficiency in modernized Wisconsin dairy herds. J. Dairy Sci. 84:705-716.

Caraviello, D. Z., K. A. Weigel, M. Craven, D. Gianola, N. B. Cook, K. V. Nordlund, P. M. Fricke, and M. C. Wiltbank. 2006. Analysis of reproductive performance of lactating cows on large dairy farms using machine learning algorithms. J. Dairy Sci. 89:4703-4722.

Contreras, L. L., C. M. Ryan, and T. R. Overton. 2004. Effects of dry cow grouping strategy and prepartum body condition score on performance and health of transition dairy cows. J. Dairy Sci. 87:517-523.

Cook, N. B., K. V. Nordlund, and G. R. Oetzel. 2004. Environmental influences on claw horn lesions associated with laminitis and subacute ruminal acidosis in dairy cows. J. Dairy Sci. 87:E36E46.

Dalton, J. C., A. Ahmadzadeh, B. Shafii, W. J. Price, and J. M. DeJarnette. 2004. Effect of simultaneous thawing of multiple 0.5 -mL straws of semen and sequence of insemination on conception rate in dairy cattle. J. Dairy Sci. 87:972-975.

de Vries, A., and C. A. Risco. 2005. Trends and seasonality of reproductive performance in Florida and Georgia dairy herds from 1976 to 2002. J. Dairy Sci. 88:3155-3165.

DeVries, T. J., M. A. G. von Keyserlingk, and K. A. Beauchemin. 2005. Frequency of feed delivery affects the behavior of lactating dairy cows. J. Dairy Sci. 88:3553-3562.

Elbers, A. R. W., J. D. Miltenburg, D. De Lange, A. P. P. Crauwels, H. W. Barkema, and Y. H. Schukken. 1998. Risk factors for clinical mastitis in a random sample of dairy herds from the southern part of The Netherlands. J. Dairy Sci. 81:420-426.

El-Zarkouny, S. Z., J. A. Cartmill, B. A. Hensley, and J. S. Stevenson. 2004. Pregnancy in dairy cows after synchronized ovulation regimens with or without presynchronization and progesterone. J. Dairy Sci. 87:1024-1037.

Fricke, P. M. 2002. Scanning the future-Ultrasonography as a reproductive management tool for dairy cattle. J. Dairy Sci. 85:1918-1926.

Godden, S. M., K. D. Lissemore, D. F. Kelton, K. E. Leslie, J. S. Walton, and J. H. Lumsden. 2001. Relationships between milk urea concentrations and nutritional management, production, and economic variables in Ontario dairy herds. J. Dairy Sci. 84:1128-1139.

Moore, K., and W. W. Thatcher. 2006. Major advances associated with reproduction in dairy cattle. J. Dairy Sci. 89:1254-1266.

Moreira, F., C. A. Risco, M. F. Pires, J. D. Ambrose, M. Drost, M. DeLorenzo, and W. W. Thatcher. 2000. Effect of body condition on reproductive efficiency of lactating dairy cows receiving a timed insemination. Theriogenology 53:1305-1319.

Navanukraw, C., D. A. Redmer, L. P. Reynolds, J. D. Kirsch, A. T. Grazul-Bilska, and P. M. Fricke. 2004. A modified presynchronization protocol improves fertility to timed artificial insemination in lactating dairy cows. J. Dairy Sci. 87:1551-1557.

Pursley, J. R., M. O. Mee, and M. C. Wiltbank. 1995. Synchronization of ovulation in dairy cows using $\mathrm{PGF}_{2 \alpha}$ and GnRH. Theriogenology 44:915-923.

Santos, J. E. P., S. O. Luchem, R. L. A. Cerri, K. N. Galvao, R. C. Chebel, W. W. Thatcher, C. S. Dei, and C. R. Bilby. 2004. Effect of $\mathrm{bST}$ and reproductive management on reproductive performance of Holstein dairy cows. J. Dairy Sci. 87:868-881. 
Sterry, R. A., M. L. Welle, and P. M. Fricke. 2006. Effect of interval from timed AI to initiation of resynchronization of ovulation on fertility of lactating dairy cows. J. Dairy Sci. 89:2099-2109.

Stevenson, J. S., and A. P. Phatak. 2005. Inseminations at estrus induced by presynchronization before application of synchronized estrus and ovulation. J. Dairy Sci. 88:399-405.

Stone, W. C. 2004. Nutritional approaches to minimize subacute ruminal acidosis and laminitis in dairy cattle. J. Dairy Sci. 87:E13- E26.

Tucker, C. B., D. M. Weary, and D. Fraser. 2004. Free-stall dimensions: Effects on preference and stall usage. J. Dairy Sci. 87:1208-1216.

Vailes, L. D., and J. H. Britt. 1990. Influence of footing surface on mounting and other sexual behaviors of estrual Holstein cows. J. Anim. Sci. 68:2333-2339.
Veerkamp, R. F., J. K. Oldenbroek, H. J. Van Der Gaast, and J. H. J. Van Der Werf. 2000. Genetic correlation between days until start of luteal activity and milk yield, energy balance, and live weights. J. Dairy Sci. 83:577-583.

Weigel, K. A., R. W. Palmer, and D. Z. Caraviello. 2003. Investigation of factors affecting voluntary and involuntary culling in expanding herds in Wisconsin using survival analysis. J. Dairy Sci. 86:1482-1486.

Westwood, C. T., I. J. Lean, and J. K. Garvin. 2002. Factors influencing fertility of Holstein dairy cows: A multivariate description. J. Dairy Sci. 85:3225-3237.

Windig, J. J., M. P. L. Calus, and R. F. Veerkamp. 2005. Influence of herd environment on health and fertility and their relationship with milk production. J. Dairy Sci. 88:335-347. 